\title{
Effects of dietary neutral detergent fiber and starch ratio on rumen epithelial cell morphological structure and gene expression in dairy cows
}

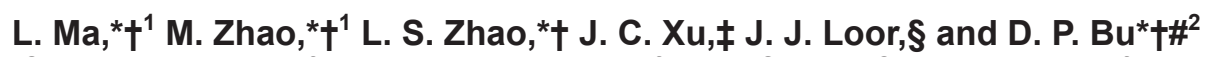 \\ *State Key Laboratory of Animal Nutrition, Institute of Animal Science, Chinese Academy of Agricultural Sciences, Beijing 100193, China \\ †Chinese Academy of Agricultural Sciences-World Agroforestry Centre (CAAS-ICRAF) Joint Laboratory on Agroforestry \\ and Sustainable Animal Husbandry, World Agroforestry Centre, East and Central Asia, Beijing 100193, China \\ ¥Kunming Institute of Botany, Chinese Academy of Sciences, Kunming, 650201, China \\ $\S$ Department of Animal Sciences and Division of Nutritional Sciences, University of Illinois, Urbana 61801 \\ \#Hunan Co-Innovation Center of Animal Production Safety (CICAPS), Changsha 410128, China
}

\begin{abstract}
This study was designed to investigate the effect of dietary neutral detergent fiber to starch ratio on rumen epithelial morphological structure and gene expression. Eight primiparous dairy cows including 4 ruminally fistulated cows were assigned to 4 total mixed rations with neutral detergent fiber to starch ratios of 0.86 , $1.18,1.63$, and 2.34 in a replicated $4 \times 4$ Latin square design. The duration of each period was $21 \mathrm{~d}$ including $14 \mathrm{~d}$ for adaptation and $7 \mathrm{~d}$ for sampling. Rumen epithelial papillae were collected from the ruminally fistulated cows for morphological structure examination and mRNA expression analysis using quantitative real-time PCR of several genes related to volatile fatty acid absorption and metabolism, and cellular growth. Increasing dietary neutral detergent fiber to starch ratio resulted in a linear increase in the thickness of the stratum spinosum and basale. In contrast, expression of $H M G C S 2$ (encoding the rate-limiting enzyme in the synthesis of ketone bodies) decreased linearly, whereas the expression of MCT2 (encoding a transporter of volatile fatty acid) increased linearly with increasing dietary neutral detergent fiber to starch ratio. As dietary neutral detergent fiber to starch ratio increased, expression of IGFBP5 (a gene related to the growth of rumen epithelial papillae) decreased, whereas IGFBP 6 expression increased. Both of these IGFBP genes are regulated by short-chain fatty acids. Overall, the data indicate that dietary neutral detergent fiber to starch ratio can alter the thickness of the rumen epithelial papillae partly through changes in expression of genes associated with regulating volatile fatty acid absorption, metabolism, and cell growth.
\end{abstract}

Received July 25, 2016.

Accepted January 18, 2017.

${ }^{1} \mathrm{~L}$. Ma and M. Zhao contributed equally.

${ }^{2}$ Corresponding author: budengpan@126.com
Key words: dairy cow, gene expression, neutral detergent fiber to starch ratio, rumen morphological

\section{INTRODUCTION}

Dietary NDF to starch ratio is a key determinant of carbohydrate composition of ruminant diets, and it could affect the composition and content of VFA in the rumen. Epithelial papillae lining the rumen increase the surface area for VFA absorption. Previous research indicated that dietary chemical composition and physical properties were the main factors affecting the morphological structure of the rumen epithelial papillae (Beharka et al., 1998; Steele et al., 2011; Liu et al., 2013). In addition, carbohydrate composition of the diet could influence the rumen environment and might affect the morphological structure of the rumen papillae (Steele et al., 2011).

The integrity of the rumen morphological structure is the key to ensuring absorption of the VFA. Classical studies indicated that 60 to $80 \%$ of the VFA were absorbed in the rumen, and VFA could supply 60 to $80 \%$ of the maintenance energy requirements of the dairy cow (Bergman, 1990; Baldwin, 1998). Although many factors affect the absorption rate of VFA by the rumen epithelium, the main factors include the carbon chain length, $\mathrm{pH}$, rumen epithelium surface area, concentration of VFA, and the osmotic pressure of the rumen fluid (Gaebel et al., 1987; Odongo et al., 2006).

Previous research demonstrated that rumen epithelial papilla development was increased by feeding a high content of digestible carbohydrate, which in turn enhanced density and surface area of the rumen epithelium, and hence, overall VFA absorption capacity (Goodlad, 1981). Thus, compared with a high-fiber diet, the ability of the rumen epithelium to absorb increasing amounts of VFA could be improved by feeding highly digestible carbohydrate such as starch (Aschenbach et al., 2009). 
rumen contents. Subsequently, the ventral wall of the rumen was retrieved through the cannula, washed, and a portion of the papillae excised and rinsed with precooled PBS buffer $(\mathrm{pH}=7.4)$. A portion of the sample was fixed with $4 \%$ formaldehyde solution for $48 \mathrm{~h}$ for analysis of epithelial morphology (Steele et al., 2011). Papilla samples were dehydrated, paraffinembedded, sliced, and stained with hematoxylin and eosin before scanning. The thickness of the stratum corneum, stratum granulosum, stratum spinosum, and basal layer cell was measured using Image-Pro Express 6.0 software (Media Cybernetics Inc., Rockville, MD) at a magnification of $20 \times$ and $40 \times$. A portion of the fresh papilla samples from each cow was preserved in liquid nitrogen before RNA extraction for gene expression analysis.

\section{RNA Extraction, Reverse Transcription, and PCR of Rumen Epithelial Papillae Samples}

Total RNA from rumen papillae samples was isolated using the TRIzol reagent (catalog no. 74106, Life
Technologies, Carlsbad, CA) according to the manufacturer's protocol. The total RNA was purified by the RNeasy mini kit (catalog no. 74106, Qiagen, Hilden, Germany) following DNase treatment using the RNaseFree DNase Set (catalog no. 79254, Qiagen). The RNA concentration was measured by a NanoDrop 1000 . The $\mathrm{A}_{260} / \mathrm{A}_{280}$ values were $\geq 1.9$. Integrity of the purified total RNA samples was assessed using an Agilent 2100 Bioanalyzer with the RNA6000 Nano Lab Chip Kit (Agilent Technologies, Santa Clara, CA). Reverse transcription was performed with reverse primer specific to each gene, and subsequent qPCR was performed using the SYBR Premix Ex TaqTM II (Perfect Real Time; TaKaRa, Tokyo, Japan; Bu et al., 2015) and specific primers (Table 2). The PCR products were sequenced to confirm the specificity of the primers. And the cycle threshold value for the reference gene ( $\beta$-actin) was 18.33. Several genes related to the absorption and metabolism of VFA and the growth of papillae were selected and detected, and the cycle threshold values ranged from 23.57 to 28.95 . The average PCR efficiency across all primers was $96 \%$.

Table 2. Primer sequences, genes targeted, and length of PCR products

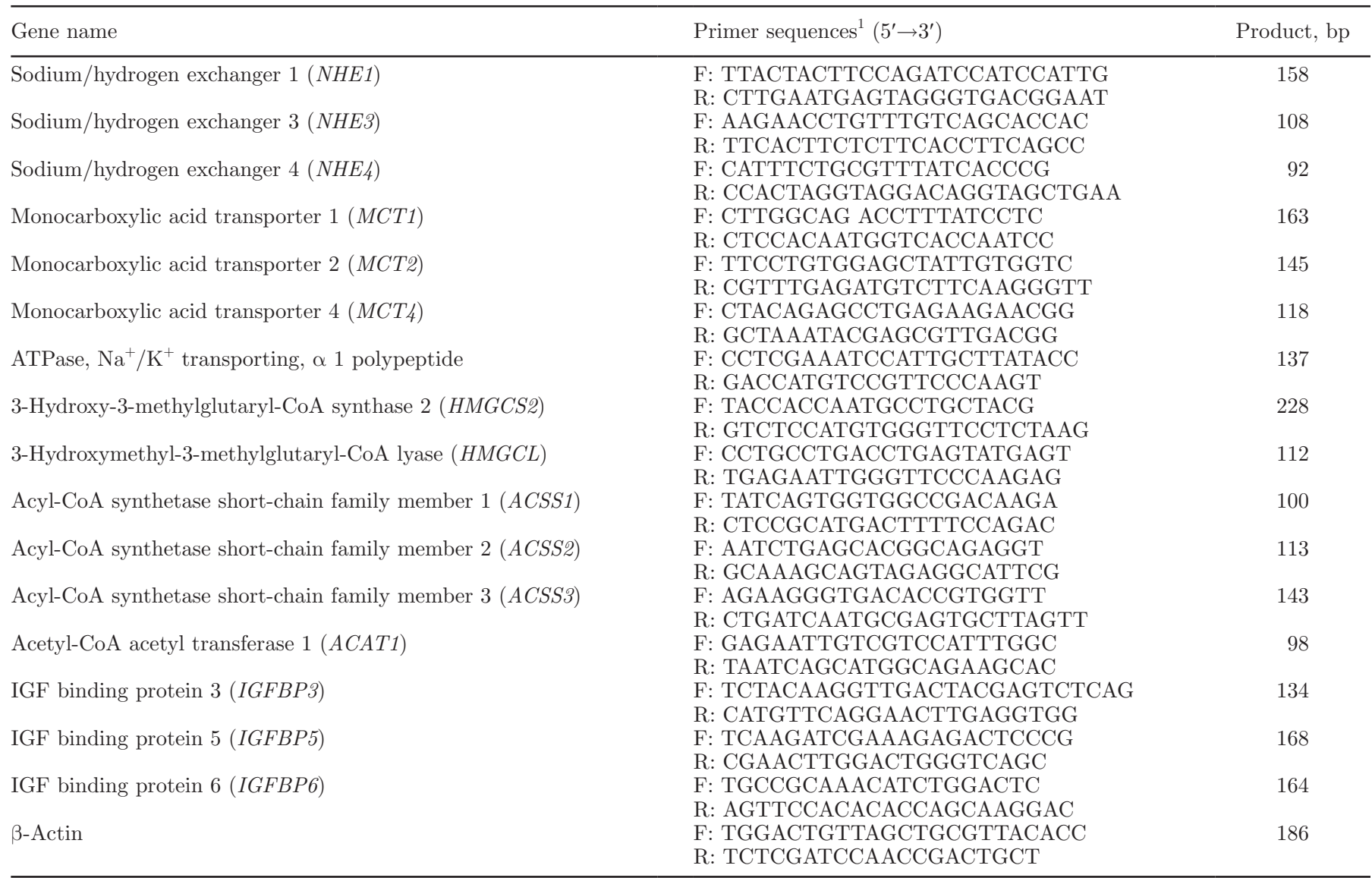

${ }^{1} \mathrm{~F}=$ forward $; \mathrm{R}=$ reverse. 
Table 3. Morphological structure of rumen papillae of cows fed NDF to starch ratios of 0.86 (T1), 1.18 (T2), 1.63 (T3), and 2.34 (T4; 36 samples analyzed)

\begin{tabular}{|c|c|c|c|c|c|c|c|c|}
\hline Item & \multicolumn{4}{|c|}{ Diets (NDF to starch ratios) } & SEM $^{1}$ & \multicolumn{3}{|c|}{$P$-value } \\
\hline Stratum granulosum, $\mu \mathrm{m}$ & 12 & 14.43 & 11.72 & 12.42 & 1.08 & 0.31 & 0.73 & 0.39 \\
\hline Stratum spinosum and stratum basale, $\mu \mathrm{m}$ & 39.58 & 42.84 & 43.24 & 54.22 & 4.93 & 0.06 & 0.02 & 0.33 \\
\hline
\end{tabular}

${ }^{1} \mathrm{SEM}=$ standard error of least squares means.

\section{Statistical Analysis}

Data were analyzed using a MIXED model in SAS (version 8.2, SAS Institute Inc., Cary, NC). The model included treatment, period, day and treatment $\times$ period interaction as fixed effects, and cow as a random effect. Significance was declared at $P<0.05$ unless otherwise noted. A trend for significance was declared at $P<0.10$. Linear and quadratic effects were analyzed with the Contrast statement in SAS.

\section{RESULTS}

\section{Effect of NDF to Starch Ratio on Morphological Structure of Rumen Epithelial Papillae}

No significant difference $(P>0.05)$ among the treatments was observed in the thickness of stratum corneum and stratum granulosum (Table 3 and Figure 1). The thickness of stratum spinosum and stratum basale increased linearly in response to increasing NDF to starch ratio $(P=0.02)$, and the average was $44.97 \mu \mathrm{m}$ (Table 3). The morphological structure of the rumen epithelium is shown in Figure 1.

\section{Effect of NDF to Starch Ratio on Gene Expression of Rumen Epithelial Papillae}

The expression of the genes involved in VFA absorption, growth, and metabolism of rumen papillae is summarized in Table 4. No significant difference among the treatments $(P>0.05)$ was observed for the expression of NHE1 and NHE3, which help maintain the acid-base balance through the exchange of $\mathrm{Na}^{+}$into and $\mathrm{H}^{+}$out of the rumen epithelial cell, but the expression of $N H E 4$ decreased linearly with increasing NDF to starch ratio $(P=0.03)$. No treatment effect was observed on the expression of MCT1, MCT4, or Na/K ATPase $(P>$ $0.05)$, but the expression of $M C T 2$ increased linearly with increasing NDF to starch ratio $(P<0.01)$.

The expression of ACSS1, ACSS2, ACSS3, and $H M G C L$, which are related to the metabolism of VFA, was not affected by the NDF to starch ratio $(P>0.05)$. However, the expression of HMGCS2, which encodes a mitochondrial enzyme that catalyzes the first reaction of ketogenesis, was downregulated with increasing NDF to starch ratio.

No effect of treatments was detected on the expression of IGFBP3 $(P>0.05)$, but the expression of $I G F B P 5$ decreased $(P<0.01)$, whereas that of IGFBP 6 increased with increasing NDF to starch ratio $(P<$ 0.01 ). These 3 genes are related to the growth of rumen epithelial cells.

\section{DISCUSSION}

The stratum corneum, granulosum, spinosum, and basale compose the epithelial papillae of the rumen. In this study, the morphology of the stratum corneum and granulosum was not affected by the NDF to starch ratio. Such response was unexpected because some evidence is available that the components of the diet are more important in influencing the thickness of the stratum corneum than influencing the absorption of nutrients (Graham and Simmons, 2005). A previous study reported that the thickness of the stratum corneum could increase up to 15 muscularis when highconcentrate diets were fed; in contrast, feeding a high forage diet decreased the stratum corneum by 3 to 4 muscularis (Gaebel et al., 1987). Although in the present study we did not observe similar kind of response with the high-forage diet, other recent data indicated that the thickness of the stratum corneum is unrelated to the level of concentrate or roughage in the diet; instead, the thickness of the stratum spinosum and basale increased with increasing proportion of roughage in the diet (Steele et al., 2011), which we also detected in the present study. Our data revealed that the thickness of the stratum spinosum and basale increased linearly with increasing dietary NDF to starch ratio, suggesting that the surface of the rumen wall and the capacity for VFA absorption could be enhanced when the dietary NDF to starch ratio increases.

Previous research indicated that 60 to $80 \%$ of the maintenance energy required by ruminants is supplied by VFA produced during carbohydrate fermentation in the rumen (Bergman, 1990; Baldwin, 1998). As reported 

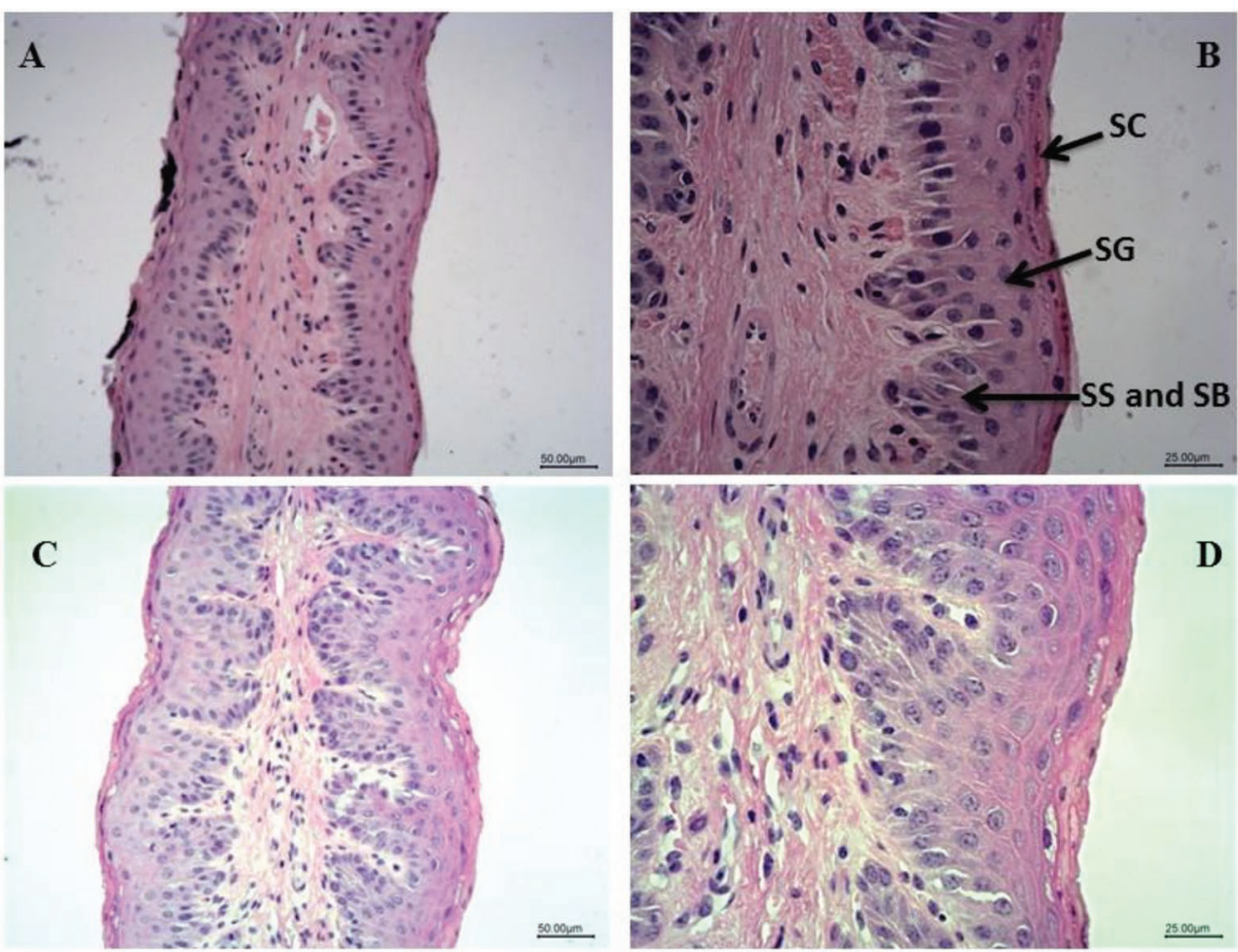

Figure 1. Microstructure of rumen epithelium of cows fed NDF to starch ratios of 0.86 (T1), 1.18, 1.63, and 2.34 (T4): T1 group (A) 200×, T1 group (B) 400×, T4 group (C) 200×, and T4 group (D) 400×. SC = stratum corneum; SG = stratum granulosum; SS = stratum spinosum; and $\mathrm{SB}=$ stratum basal. Color version available online.

in our previous publication from this same experiment (Zhao et al., 2016), the proportion of acetate (from 57.2 to $62.8 \%, P<0.01)$ and the acetate to propionate ratio $(2.49$ to $2.95, P<0.01)$ increased linearly in response to increased dietary NDF to starch ratio. The mechanisms allowing for the transport of VFA through

Table 4. Expression of genes involved in VFA absorption, growth, and metabolism of rumen papilla cells of dairy cows fed NDF to starch ratios of 0.86 (T1), 1.18 (T2), 1.63 (T3), and 2.34 (T4; 12 samples analyzed)

\begin{tabular}{|c|c|c|c|c|c|c|c|c|}
\hline Gene symbol & \multicolumn{4}{|c|}{ Diet (NDF to starch ratios) } & $\mathrm{SEM}^{1}$ & \multicolumn{3}{|c|}{$P$-value } \\
\hline NHE4 & 1.13 & 0.61 & 0.19 & 0.41 & 0.25 & 0.06 & 0.03 & 0.07 \\
\hline MCT1 & 1.26 & 1.03 & 1.26 & 1.09 & 0.27 & 0.9 & 0.82 & 0.9 \\
\hline MCT2 & $0.65^{\mathrm{b}}$ & $0.72^{\mathrm{b}}$ & $0.74^{\mathrm{b}}$ & $1.13^{\mathrm{a}}$ & 0.12 & 0.01 & $<0.01$ & 0.07 \\
\hline HMGCS2 & 1.16 & 0.95 & 0.72 & 0.65 & 0.13 & 0.09 & 0.02 & 0.62 \\
\hline$A C S S 1$ & 1.07 & 1.16 & 1.18 & 1.45 & 0.27 & 0.75 & 0.34 & 0.74 \\
\hline ACSS2 & 1.08 & 0.98 & 1 & 0.72 & 0.22 & 0.72 & 0.33 & 0.71 \\
\hline ACSS3 & 0.67 & 1.91 & 1.09 & 1.29 & 0.3 & 0.14 & 0.49 & 0.16 \\
\hline$H M G C L$ & 1.1 & 1.18 & 1.01 & 0.89 & 0.19 & 0.76 & 0.37 & 0.62 \\
\hline$A C A T 1$ & 1.15 & 1.08 & 0.78 & 1.09 & 0.81 & 0.81 & 0.69 & 0.51 \\
\hline IGFBP3 & 1.47 & 1.35 & 1.17 & 1.37 & 0.24 & 0.89 & 0.71 & 0.57 \\
\hline
\end{tabular}

${ }^{\mathrm{a}, \mathrm{b}}$ Least squares means within a row with different superscripts differ $(P<0.05)$.

${ }^{1} \mathrm{SEM}=$ standard error of least squares means. 
the basement membrane are still unknown, but several studies indicated that $M C T$ plays an important role in this process.

In nonruminants, a total of 14 members of the $M C T$ family have been described, and MCT1 to MCT4 are believed to participate in the transfer of monocarboxylic acids such as lactic acid, pyruvic acid, and ketone bodies (Halestrap and Price, 1999; Halestrap and Meredith, 2004). Both MCT1 and MCT4 were confirmed to participate in the process of VFA transfer through the basement membrane (Kirat et al., 2006; Yan et al., 2014). Other research indicated that MCT1 and MCT2 are expressed in rumen epithelial cells, but whether they affect the transfer of VFA through the membrane is unknown (Graham et al., 2007). In this study, the expression of MCT1 and MCT4 was not affected by the ratio of NDF to starch, but the expression of MCT2 increased as the NDF to starch ratio increased. Thus, the positive correlation between $M C T 2$ and rumen acetate concentration (Zhao et al., 2016) as NDF to starch ratio increased strongly suggest that $M C T 2$ could be responsible for enhancing VFA absorption through the basement membrane.

The concentration of $\mathrm{H}^{+}$within the rumen epithelial cells increases during the dissociation of $\mathrm{H}^{+}$from the VFA, and it plays an important role in maintaining of the acid-base balance inside cells. As reported in our previous study (Zhao et al., 2016), rumen $\mathrm{pH}$ was monitored continuously for 3 consecutive days on d 18 , 19 , and 20 during each period by placing indwelling $\mathrm{pH}$ probes into the rumen as described in a previous study (Gozho et al., 2006). The $\mathrm{pH}$ data were summarized as average $\mathrm{pH}$, time below $\mathrm{pH} 5.6,5.8$, and 6.0 for each 24 -h period. The average rumen $\mathrm{pH}$ increased linearly $(5.90,6.03,6.08$, and 6.26$)$ in response to the increased dietary NDF to starch ratio, whereas the daily duration of rumen $\mathrm{pH}$ below 5.6, 5.8, and 6.0 decreased linearly (267.3, 90.3, 85.3, and 4.07; 583.5, 290.2, 239.7, and $52.5 ; 885.8,655.2,552.4$, and 188.1 , respectively; Zhao et al., 2016). It is possible that the cows fed the diet with 0.86 as the dietary NDF to starch ratio might have suffered from SARA, which is defined as the time of $\mathrm{pH}$ below 5.6 of least $180 \mathrm{~min} / \mathrm{d}$ (Khafipour et al., 2009). The protein $N H E$ on the cell membrane helps maintain the acid-base balance through the exchange of $\mathrm{Na}^{+}$into and $\mathrm{H}^{+}$out of the cell (Yang et al., 2012). Previous studies revealed that the expression of $N H E$ was upregulated by an increase in VFA concentration (Diernaes et al., 1994; Sehested et al., 1996). In this study, the expression of NHE1 and NHE3 was not affected by the carbohydrate composition of the diet, whereas the expression of NHE4 was linearly downregulated in response to increasing NDF to starch ratio. This response suggests that NHE4 may act as a mechanism to help maintain the acid-base balance within rumen epithelial cells.

The $\mathrm{Na}^{+} / \mathrm{K}^{+}$ATPase is an important transporter in rumen epithelial cells and plays a role in maintaining the electrochemical gradient and the balance of $\mathrm{Na}^{+}$ and $\mathrm{K}^{+}$within the cells. In a previous study, the expression of $\mathrm{Na}^{+} / \mathrm{K}^{+}$ATPase was upregulated after feeding a high-concentrate/low-forage diet (McLeod and Baldwin, 2000). However, in the present study, the expression of $\mathrm{Na}^{+} / \mathrm{K}^{+}$ATPase was not significantly affected by the carbohydrate component in the diet.

Most of the absorbed VFA, including acetic acid and propionic acid, are taken up into the portal vein. In mature ruminants, $95 \%$ of the butyric acid is typically absorbed by rumen epithelial cells and metabolized into ketone bodies (Sehested et al., 1999); however, in calves the proportion of butyric acid was estimated at 33 to $78 \%$ (Weigand et al., 1972). Feeding a high-concentrate to forage diet increased the absorption of acetic acid in bulls as a result of greater activity of acyl-CoA acyltransferase ( $A C A T 1$ : the enzyme catalyzing the synthesis of acetoacetyl-CoA from 2 acetyl-CoA) in rumen epithelial papillae (Harmon et al., 1991). Although we did not measure the expression of $A C A T 1$, the lack of change in expression of the ACSS genes suggests that enhanced uptake of VFA in response to increasing NDF to starch ratio may not involve a change in gene transcription of the enzymes responsible for charging the VFA to an acyl-CoA. A recent study with dairy cows also did not detect changes in ruminal acetic acid metabolism as a result of differences in dietary carbohydrate composition, but the authors indicated that an increase in acetyl-CoA pool size could be expected as a high VFA concentration was present in the rumen (Penner et al., 2009).

Beta-hydroxybutyric acid is the main ketone body in the blood of dairy cows, and during periods of positive energy balance it is produced primarily via ketogenesis from butyrate within the rumen epithelial cells. As the rate-limiting enzyme in the synthesis of ketone bodies, the HMGCS2 protein plays an important role in the metabolism of VFA within the rumen epithelium. At least in nonruminants, the protein concentration of $H M G C S 2$ is strongly regulated at the transcriptional level (Nakamura et al., 2014). In the present study, the expression of HMGCS2 was downregulated as the NDF to starch ratio increased, which indicates that the synthesis of ketone bodies can potentially decrease as the proportion of NDF in the diet increases. A previous study reported no difference in the expression of genes related to the synthesis and metabolism of ketone bodies in rumen epithelial cells as the ratio of concentrate to forage changed (Penner et al., 2009). However, among ketogenic genes, the expression of $H M G C L$ was 
upregulated with the increase of dietary concentrate (Naeem et al., 2012). The exact mechanism responsible for the linear downregulation of HMGCS2 as the NDF to starch ratio increased is unknown.

The growth of rumen epithelial cells is closely related to diet composition. Several studies reported that genes in the $I G F$ family play a role in the development of rumen epithelial cells (Shen et al., 2004; Kaulfuss et al., 2009). A high level of digestible carbohydrates in the diet or an increase in the concentration of butyrate increased activation of $I G F B P$ and led to greater proliferation and differentiation of rumen epithelial cells (Baixeras et al., 2001; Firth and Baxter, 2002). During incubations of small intestinal epithelial cells without the addition of exogenous $I G F-1$, the expression of $I G F B P$ was upregulated by exogenous VFA (Sanderson, 2004). Upregulation of IGFBP expression by exogenous VFA also increased the proliferation of intestinal epithelial cells (Nishimura et al., 1998).

In cattle, the expression of IGFBP3 and IGFBP6 was downregulated, whereas IGFBP5 expression was upregulated when the level of grain in the diet increased (Steele et al., 2011). In the present study, as dietary NDF to starch ratio increased, the expression of IGFBP 5 was downregulated, whereas IGFBP 6 expression was upregulated. Both IGFBP 5 and IGFBP 6 are considered to be closely related to rumen papilla growth, and our data are in accordance with the results of Steele et al. (2011). The proliferative capability of cells can be increased by IGFBP6 (Baxter, 2001; Firth and Baxter, 2002), but the protein can also function as a repressor when combined with IGF-2 (Bach, 2005). Because changes in rumen morphology were accompanied by variations in the number of $I G F-1 R$ in the rumen epithelium, it is likely that the $I G F B P$ is important in the control of rumen epithelial cell growth (Shen et al., 2004). The exact regulatory mechanisms require further research.

\section{CONCLUSIONS}

An increase in dietary NDF to starch ratio increased the thickness of the stratum spinosum and basale in rumen epithelial papillae, and altered the expression of genes related to VFA absorption, metabolism, and papilla cell growth. These responses suggest that VFA production increased as the ratio of NDF to starch increased such that changes in gene transcription may have allowed for greater transport of the VFA into the rumen epithelium. Whether the diet elicited carryover effects on gene expression could not be evaluated. Further studies should be conducted to investigate the relationship between experimental period length and gene expression profiles.

\section{ACKNOWLEDGMENTS}

This research was supported by fund from a grant (no. 2012BAD12B02-5) from Ministry of Science and Technology of China, the Agriculture Science and Technology Innovation Program (ASTIP-IAS07), and by a Research Program of the State Key Laboratory of Animal Nutrition (2004DA125184G1103).

\section{REFERENCES}

Allen, M. S. 1997. Relationship between fermentation acid production in the rumen and the requirement for physically effective fiber. J. Dairy Sci. 80:1447-1462.

Armentano, L., and M. Pereira. 1997. Measuring the effectiveness of fiber by animal response trials. J. Dairy Sci. 80:1416-1425.

Aschenbach, J. R., S. Bilk, G. Tadesse, F. Stumpff, and G. Gabel. 2009. Bicarbonate-dependent and bicarbonate-independent mechanisms contribute to nondiffusive uptake of acetate in the ruminal epithelium of sheep. Am. J. Physiol. Gastrointest. Liver Physiol. 296:G1098-G1107.

Bach, L. A. 2005. IGFBP-6 five years on; not so 'forgotten'? Growth Horm. IGF Res. 15:185-192.

Baixeras, E., S. Jeay, P. A. Kelly, and M. C. Postel-Vinay. 2001. The proliferative and antiapoptotic actions of growth hormone and insulin-like growth factor-1 are mediated through distinct signaling pathways in the pro-B Ba/F3 cell line. Endocrinology 142:29682977.

Baldwin, R. L., VI 1998. Use of isolated ruminal epithelial cells in the study of rumen metabolism. J. Nutr. 128:293S-296S.

Baxter, R. C. 2001. Signalling pathways involved in antiproliferative effects of IGFBP-3: A review. Mol. Pathol. 54:145-148.

Beckman, J. L., and W. P. Weiss. 2005. Nutrient digestibility of diets with different fiber to starch ratios when fed to lactating dairy cows. J. Dairy Sci. 88:1015-1023.

Beharka, A. A., T. G. Nagaraja, J. L. Morrill, G. A. Kennedy, and R. D. Klemm. 1998. Effects of form of the diet on anatomical, microbial, and fermentative development of the rumen of neonatal calves. J. Dairy Sci. 81:1946-1955.

Bergman, E. N. 1990. Energy contributions of volatile fatty acids from the gastrointestinal tract in various species. Physiol. Rev. 70:567-590.

Bu, D. P., X. M. Nan, F. Wang, J. J. Loor, and J. Q. Wang. 2015. Identification and characterization of microRNA sequences from bovine mammary epithelial cells. J. Dairy Sci. 98:1696-1705.

Diernaes, L., J. Sehested, P. D. Moller, and E. Skadhauge. 1994. Sodium and chloride transport across the rumen epithelium of cattle in vitro: effect of short-chain fatty acids and amiloride. Exp. Physiol. 79:755-762.

Firth, S. M., and R. C. Baxter. 2002. Cellular actions of the insulinlike growth factor binding proteins. Endocr. Rev. 23:824-854.

Gaebel, G., H. Martens, M. Suendermann, and P. Galfi. 1987. The effect of diet, intraruminal $\mathrm{pH}$ and osmolarity on sodium, chloride and magnesium absorption from the temporarily isolated and washed reticulo-rumen of sheep. Q. J. Exp. Physiol. 72:501-511.

Goodlad, R. A. 1981. Some effects of diet on the mitotic index and the cell cycle of the ruminal epithelium of sheep. Q. J. Exp. Physiol. 66:487-499.

Gozho, G. N., D. O. Krause, and J. C. Plaizier. 2006. Rumen lipopolysaccharide and inflammation during grain adaptation and subacute ruminal acidosis in steers. J. Dairy Sci. 89:4404-4413.

Graham, C., I. Gatherar, I. Haslam, M. Glanville, and N. L. Simmons. 2007. Expression and localization of monocarboxylate transporters and sodium/proton exchangers in bovine rumen epithelium. Am. J. Physiol. Regul. Integr. Comp. Physiol. 292:R997-R1007.

Graham, C., and N. L. Simmons. 2005. Functional organization of the bovine rumen epithelium. Am. J. Physiol. Regul. Integr. Comp. Physiol. 288:R173-181. 
Halestrap, A. P., and D. Meredith. 2004. The SLC16 gene family-from monocarboxylate transporters (MCTs) to aromatic amino acid transporters and beyond. Pflugers Arch. 447:619-628.

Halestrap, A. P., and N. T. Price. 1999. The proton-linked monocarboxylate transporter (MCT) family: Structure, function and regulation. Biochem. J. 343:281-299.

Harmon, D. L., K. L. Gross, C. R. Krehbiel, K. K. Kreikemeier, M. L. Bauer, and R. A. Britton. 1991. Influence of dietary forage and energy intake on metabolism and acyl-CoA synthetase activity in bovine ruminal epithelial tissue. J. Anim. Sci. 69:4117-4127.

Kaulfuss, S., P. Burfeind, J. Gaedcke, and J. G. Scharf. 2009. Dual silencing of insulin-like growth factor-I receptor and epidermal growth factor receptor in colorectal cancer cells is associated with decreased proliferation and enhanced apoptosis. Mol. Cancer Ther. 8:821-833.

Khafipour, E., D. O. Krause, and J. C. Plaizier. 2009. Alfalfa pelletinduced subacute ruminal acidosis in dairy cows increases bacterial endotoxin in the rumen without causing inflammation. J. Dairy Sci. 92:1712-1724.

Kirat, D., J. Masuoka, H. Hayashi, H. Iwano, H. Yokota, H. Taniyama, and S. Kato. 2006. Monocarboxylate transporter 1 (MCT1) plays a direct role in short-chain fatty acids absorption in caprine rumen. J. Physiol. 576:635-647.

Liu, J. H., T. T. Xu, Y. J. Liu, W. Y. Zhu, and S. Y. Mao. 2013 A high-grain diet causes massive disruption of ruminal epithelial tight junctions in goats. Am. J. Physiol. Regul. Integr. Comp. Physiol. 305:R232-R241.

McLeod, K. R., and R. L. Baldwin VI.. 2000. Effects of diet forage:concentrate ratio and metabolizable energy intake on visceral organ growth and in vitro oxidative capacity of gut tissues in sheep. J. Anim. Sci. 78:760-770.

Naeem, A., J. K. Drackley, J. Stamey, and J. J. Loor. 2012. Role of metabolic and cellular proliferation genes in ruminal development in response to enhanced plane of nutrition in neonatal Holstein calves. J. Dairy Sci. 95:1807-1820.

Nakamura, M. T., B. E. Yudell, and J. J. Loor. 2014. Regulation of energy metabolism by long-chain fatty acids. Prog. Lipid Res. $53: 124-144$.

Nishimura, A., M. Fujimoto, S. Oguchi, R. D. Fusunyan, R. P. MacDermott, and I. R. Sanderson. 1998. Short-chain fatty acids regulate IGF-binding protein secretion by intestinal epithelial cells. Am. J. Physiol. 275:E55-E63.

Odongo, N. E., O. Alzahal, M. I. Lindinger, T. F. Duffield, E. V. Valdes, S. P. Terrell, and B. W. McBride. 2006. Effects of mild heat stress and grain challenge on acid-base balance and rumen tissue histology in lambs. J. Anim. Sci. 84:447-455.
Penner, G. B., M. Taniguchi, L. L. Guan, K. A. Beauchemin, and M. Oba. 2009. Effect of dietary forage to concentrate ratio on volatile fatty acid absorption and the expression of genes related to volatile fatty acid absorption and metabolism in ruminal tissue. J. Dairy Sci. 92:2767-2781.

People's Republic of China. 2004. Feeding Standard of Dairy Cattle. China NY/t34 (China NongYe HangYe Biaozhun/Tuijian-34). China Agricultural Publisher, Beijing, China.

Sanderson, I. R. 2004. Short chain fatty acid regulation of signaling genes expressed by the intestinal epithelium. J. Nutr. 134:2450S$2454 \mathrm{~S}$.

Sehested, J., L. Diernaes, P. D. Moller, and E. Skadhauge. 1996. Transport of sodium across the isolated bovine rumen epithelium interaction with short-chain fatty acids, chloride and bicarbonate. Exp. Physiol. 81:79-94.

Sehested, J., L. Diernaes, P. D. Moller, and E. Skadhauge. 1999 Transport of butyrate across the isolated bovine rumen epithelium-interaction with sodium, chloride and bicarbonate. Comp. Biochem. Physiol. A 123:399-408.

Shen, Z. H. M. Seyfert, B. Lohrke, F. Schneider, R. Zitnan, A. Chudy, S. Kuhla, H. M. Hammon, J. W. Blum, H. Martens, H. Hagemeister, and J. Voigt. 2004. An energy-rich diet causes rumen papillae proliferation associated with more IGF type 1 receptors and increased plasma IGF-1 concentrations in young goats. J. Nutr. 134:11-17.

Steele, M. A., J. Croom, M. Kahler, O. AlZahal, S. E. Hook, K. Plaizier, and B. W. McBride. 2011. Bovine rumen epithelium undergoes rapid structural adaptations during grain-induced subacute ruminal acidosis. Am. J. Physiol. Regul. Integr. Comp. Physiol. 300:R1515-R1523.

Weigand, E., J. W. Young, and A. D. McGilliard. 1972. Extent of butyrate metabolism by bovine ruminoreticulum epithelium and the relationship to absorption rate. J. Dairy Sci. 55:589-597.

Yan, L., B. Zhang, and Z. Shen. 2014. Dietary modulation of the expression of genes involved in short-chain fatty acid absorption in the rumen epithelium is related to short-chain fatty acid concentration and $\mathrm{pH}$ in the rumen of goats. J. Dairy Sci. 97:5668-5675.

Yang, W., Z. Shen, and H. Martens. 2012. An energy-rich diet enhances expression of $\mathrm{Na}(+) / \mathrm{H}(+)$ exchanger isoform 1 and 3 messenger RNA in rumen epithelium of goat. J. Anim. Sci. 90:307-317.

Zhao, M., D. Bu, J. Wang, X. Zhou, D. Zhu, T. Zhang, J. Niu, and L. Ma. 2016. Milk production and composition responds to dietary neutral detergent fiber and starch ratio in dairy cows. Anim. Sci. J. 87:756-766 